\title{
A COMPETIÇÃO BASEADA NO TEMPO: UM ESTUDO DE CASO NA INDÚSTRIA MOVELEIRA DO RIO DE JANEIRO
}

\section{THE TIME-BASED COMPETITION: A CASE STUDY IN THE RIO DE JANEIRO FURNITURE INDUSTRY}

\author{
Iara Tammela \\ Doutoranda \\ COPPE/Universidade Federal do Rio de Janeiro \\ Programa de Engenharia de Produção \\ Caixa Postal 68507 \\ 21941-972 - Rio de Janeiro - RJ \\ iaratammela@terra.com.br \\ Alberto Gabbay Canen \\ Professor \\ COPPE/Universidade Federal do Rio de Janeiro \\ Programa de Engenharia de Produção \\ Caixa Postal 68507 \\ 21941-972 - Rio de Janeiro - RJ \\ agcanen@pep.ufrj.br
}

\begin{abstract}
RESUMO
A abertura comercial e a globalização das atividades econômicas têm introduzido novas formas de estratégias competitivas entre as empresas. A indústria brasileira de móveis não está imune em relação a esse novo contexto mundial. As mudanças de mercado afetam todo o setor e a busca pela qualidade com o fim de satisfazer às necessidades do cliente torna as empresas cada vez mais competitivas. Este artigo tem como objetivo mostrar como a Competição Baseada no Tempo (TBC) pode ser uma estratégia eficaz para as indústrias moveleiras brasileiras obterem uma vantagem competitiva sustentável, no que concerne à introdução rápida de novos produtos, a satisfação dos clientes aliados à qualidade e custos competitivos. Será mostrado, também, um estudo de caso numa indústria moveleira, no Rio de Janeiro, onde a aplicação da TBC e suas perspectivas são discutidas "in loco".
\end{abstract}

Palavras-chaves: Competição Baseada no Tempo, Vantagem Competitiva, Indústria Moveleira.

\begin{abstract}
Commercial opening and the globalization of economic activities have introduced new forms of competitive strategies among organizations. The Brazilian furniture industry is not impervious to that new world context. The changes in the market affect the whole sector and the search for quality so as to meet customers' demands make organizations more and more competitive. This article aims to discuss the extent to which the Time-Based Competition (TBC) can represent an efficient strategy for Brazilian furniture industry to gain sustainable competitive advantage relative to the quick introduction of new products, customers' satisfaction and competitive and cost-effective quality. The article will also discuss a case study in a furniture company located in Rio de Janeiro, where the application of TBC and its perspectives are analyzed "in loco".

Key-words: Time-Based Competition, Competitive Advantage, Furniture Industry.
\end{abstract}




\section{INTRODUÇÃO}

Num mundo globalizado, onde proliferam os acordos de livre comércio, as empresas estão buscando, cada vez mais, estratégias competitivas eficazes que as ajudem a se manter e crescer num mercado em constante mutação, no qual uma estratégia eficaz é crucial. Para sustentar uma vantagem competitiva, as empresas devem decidir como se diferenciar dos concorrentes e agregar valor aos seus produtos. Assim sendo, elas devem desenvolver produtos inovadores com qualidade e reagir rapidamente às necessidades do cliente.

De acordo com Gaither e Frazier (2001), empresas competitivas são as que oferecem os seus produtos com o maior valor agregado pelo menor custo e com o menor tempo de resposta. Uma resposta rápida às demandas de mercado constitui uma vantagem competitiva poderosa e sustentável, pois o tempo tem se destacado como a dimensão predominante da competição global, mudando fundamentalmente a forma pela qual as organizações competem. Não basta que as empresas produzam com alta qualidade e baixo custo. Para serem bem sucedidas nos dias de hoje, elas também deverão ser as primeiras a levar produtos e serviços aos clientes. Nesse novo ambiente, o ciclo do pedido (o tempo transcorrido entre o momento em que um cliente faz um pedido até o recebimento deste) deve ser drasticamente reduzido.

Este cenário de competição acirrada gerou um novo paradigma de estratégia competitiva: a competição baseada no tempo (TBC), pela qual se determina uma estratégia baseada na introdução rápida de novos produtos e compreensão das necessidades dos clientes, aliadas à qualidade e a custos competitivos (HUM e SIM, 1996). A essência da TBC envolve a redução do tempo em cada fase da criação do produto e do ciclo de entrega, traduzindo-se numa fonte significativa de vantagem competitiva sustentável (Stalk e Hout, 1988), e este é 
um conceito que se aplica a qualquer tipo de negócio, tanto para a indústria de serviços quanto para a indústria manufatureira, na qual a indústria moveleira está inserida.

A indústria moveleira brasileira é um setor em franco crescimento, principalmente em relação às exportações. Segundo a Formóbile (2004, p.15) “o segmento de mobiliário tem crescido numa média superior à economia nacional. Em 2002, por exemplo, o Brasil apresentou um crescimento que não passou de $2 \%$, enquanto o mercado interno de móveis apresentou uma expansão de 6\%". As exportações, hoje, são o foco das indústrias moveleiras e, conseqüentemente, se faz necessária uma estratégia sustentável frente aos mercados externos. Assim sendo, a diminuição do tempo em cada fase do processo, da criação à entrega de um produto, aliado às necessidades dos clientes, vem a ser a grande arma para a conquista de uma estratégia eficaz e sustentável de mercado, sendo que é neste ponto que a TBC aparece como uma estratégia eficaz para as empresas conquistarem uma posição líder de mercado frente aos seus concorrentes.

\section{A COMPETIÇÃO BASEADA NO TEMPO}

A competição baseada no tempo (TBC) surgiu como o novo paradigma de competitividade dos anos 90, devido à constante evolução das estratégias competitivas das empresas japonesas ao longo dos anos. A primeira menção sobre TBC na literatura especializada, ao que tudo indica, é atribuída a Stalk (1988). Essa constante busca pela liderança competitiva fez com que as empresas despertassem para a importância do tempo como uma vantagem sustentável na obtenção da primazia de mercado. O referido autor colocou o tempo como a máxima da vantagem competitiva e afirmou que o modo pelo qual as empresas líderes gerenciam o tempo na produção, no desenvolvimento e na introdução de novos produtos, nas vendas e na distribuição, representa a mais nova fonte de vantagem 
competitiva. Portanto, o tempo é tão importante quanto o dinheiro, a produtividade, a qualidade e a inovação.

As empresas que adotam a TBC possuem vários aspectos em comum, tais como: menor tempo de ciclo, menor tempo de resposta às necessidades do mercado, menor tempo de desenvolvimento e introdução de novos produtos, menor tempo decorrido entre uma ordem e a entrega do produto, uma resposta em tempo real às necessidades dos clientes (STALK e WEBBER, 1993), redução do tempo de valor não agregado aos sistemas seja na manufatura ou na indústria de serviços (SCHAENZER, 2000), flexibilidade, agilidade de produção e maior velocidade (WILLIS, 1998). De acordo com Stalk (1988) as fábricas são localizadas próximas aos seus clientes e as estruturas organizacionais permitem uma resposta rápida às suas necessidades. É importante salientar que aspectos políticos podem interferir no processo de localização das mesmas. As empresas se concentram na diminuição e até eliminação de atrasos que possam existir e usam a vantagem na resposta rápida para atrair os clientes mais lucrativos. Assim sendo, a redução do tempo em cada aspecto dos negócios faz com que estas empresas também reduzam os custos, melhorem a qualidade de seus produtos e fiquem mais próximas dos seus clientes, aumentando conseqüentemente o lucro, a participação no mercado e a competitividade.

O grande objetivo das empresas competidoras baseadas no tempo é a vantagem competitiva sustentável que pode ser obtida através da resposta às necessidades e expectativas dos consumidores, levando produtos e serviços melhores e mais rápidos do que os concorrentes. Assim sendo, o tempo aparece como uma solução para a busca de liderança, ganho de mercado, aumento de lucro, aumento de "market-share" e uma posição sustentável frente à concorrência. (SCHAENZER, 2000; CARTER, MELNYK e HANDFIELD, 1995). 


\subsection{Algumas estratégias para tornar uma empresa competidora baseada no tempo}

Existem várias estratégias para uma empresa se tornar competidora baseada no tempo. Stalk e Hout (1990) argumentam que, para as empresas terem sucesso, o foco gerencial deve ser na flexibilidade e na velocidade das respostas, onde os seguintes métodos devem ser utilizados: determinar o tempo como o gerenciador crítico e o parâmetro estratégico; usar a resposta rápida para estar próximo aos seus clientes; direcionar o seu sistema de valor aos clientes mais atrativos; estabelecer o passo da inovação dos seus negócios e assim, crescer mais rápido e com lucros mais altos do que a concorrência. Assim sendo, de acordo com os referidos autores, as empresas devem ter um sistema que seja de duas a três vezes mais rápido e flexível que o sistema dos concorrentes e responder prontamente às necessidades dos clientes. A empresa deve, também, ter visão, tomar decisões, fazer mudanças necessárias e sustentar as melhorias.

De Toni e Meneghetti (2000) resumiram os vários os autores que falam da TBC, suas vantagens competitivas e estratégias. Não discutem, porém, se existe uma distinção na maneira em como as empresas decidem competir, i.e., se a estratégia da empresa é focada na resposta rápida aos clientes e/ou na produção e inovação. Os autores sugerem uma classificação para os três tipos diferentes de estratégias em que os competidores baseados no tempo podem estar inseridos: com foco no produto, no processo ou tanto no produto quanto no processo. De acordo com o foco estratégico, foram descritos vários passos para se alcançar à competitividade e as empresas se tornarem competidoras no tempo.

Carter, Melnyk e Handfield (1995) também separam as empresas de acordo com o foco estratégico, porém destacam duas formas de competição: competidores rápidos para o mercado e competidores rápidos no produto. Os autores apresentaram sete estratégias fundamentais para a implementação da TBC: 1) a simplificação do sistema; 2) a integração do sistema; 3) a padronização; 4) as atividades paralelas; 5) O controle da variância; 6) a 
automação e 7) o excesso de recursos. Estas estratégias lidam com os problemas de 'qeadtime" do desenvolvimento e fabricação do produto (foco no mercado) e da colocação de uma ordem até a sua entrega (foco no produto).

Dumaine (1989), por sua vez, cita algumas táticas gerenciais para aumentar a velocidade nas operações de uma empresa, tais como: escolher um ponto de partida, diminuir a burocracia gerencial, dar maior autoridade às equipes de trabalho, devotar-se à programação e horários, lembrar-se do papel da distribuição e colocar a velocidade, e o tempo na cultura da empresa e dos funcionários. Em contrapartida, Willis (1998) apresenta uma estratégia mais operacional, para as empresas de manufatura, baseada na adoção da flexibilidade e agilidade da produção e um modelo operacional focado na ordem de pedido dos clientes (ciclo de pedido), no sistema de entregas, no desenvolvimento de produtos, no processo de produção e na rede de fornecedores.

Conforme pode ser observado, existem várias estratégias a serem seguidas pelas empresas para que estas adotem a TBC. O problema é determinar qual atende melhor às necessidades e objetivos de uma determinada empresa, seja de pequeno, médio ou grande porte em um determinado ramo de negócios, no caso, o ramo da indústria moveleira. O que deve se ter em mente é que este processo deve ter a participação de todos os setores da empresa, ou seja, da alta administração aos mais baixos escalões hierárquicos da organização. A idéia da mudança deve ser compartilhada por todos, de modo que o empreendimento não esteja fadado ao fracasso.

\section{AS EMPRESAS MOVELEIRAS BRASILEIRAS}

A indústria brasileira de móveis, segundo a Abimóvel (Associação Brasileira das Indústrias do Mobiliário, 2003, p.03): 
(...) é constituída por mais de 15.000 micro, pequenas e médias empresas que geram mais de 177.000 empregos, de capital nacional em sua maioria, distribuídas assim no país: 11.500 micro-empresas, 3.000 pequenas empresas e 500 médias empresas. Essas empresas localizam-se em sua maioria m região centro-sul do país, constituindo em alguns estados, pólos moveleiros, a exemplo de Bento Gonçalves, no Rio Grande do Sul; São Bento do Sul, em Santa Catarina; Arapongas no Paraná; Mirassol, Votuporanga e São Paulo, em São Paulo; Ubá em Minas Gerais e Linhares no Espírito Santo.

São empresas basicamente familiares, tradicionais e de capital inteiramente nacional, na sua grande maioria. É uma indústria muito fragmentada, caracterizada pelo elevado número de micro e pequenas empresas, como enfatizado acima, grande absorção de mão-de-obra e heterogeneidade tecnológica, principalmente com relação às micro e pequenas empresas, que apresentam pouca ou mínima capacitação tecnológica.

De acordo com a Abimóvel (2003), são consideradas empresas médias as que possuem acima de 150 empregados; pequenas de 15 até 150 empregados e micro empresas as que têm até 15 empregados. O BNDES (Banco Nacional de Desenvolvimento Econômico e Social, 2004) e o SEBRAE (Serviço Brasileiro de Apoio às Micro e Pequenas Empresas, 2003), por sua vez, classificam as empresas de acordo com a sua receita operacional bruta.

\begin{tabular}{|c|c|c|c|}
\hline & ABIMÓVEL & SEBRAE & BNDES \\
\hline Empresd Critério & $\begin{array}{l}\text { Numero de } \\
\text { empregados }\end{array}$ & $\begin{array}{c}\text { Receita operacional } \\
\text { bruta ou anualizada (em } \\
\text { Reais) }\end{array}$ & $\begin{array}{c}\text { Receita operacional } \\
\text { bruta ou anualizada } \\
\text { (em Reais) }\end{array}$ \\
\hline Micro empresa & Até 15 empregados. & Até $R \$ 244.000$ & Até $\mathrm{R} \$ 1.200 .000$. \\
\hline $\begin{array}{l}\text { Pequena } \\
\text { empresa }\end{array}$ & $\begin{array}{l}\text { De } 15 \text { até } 150 \\
\text { empregados. }\end{array}$ & $\begin{array}{c}\text { De } R \$ 244.000 \text { até } R \$ \\
1.200 .000\end{array}$ & $\begin{array}{c}\text { Superior a } R \$ \\
1.200 .000 \text { e inferior } \\
\text { ou igual a } R \$ \\
10.500 .000\end{array}$ \\
\hline Média empresa & $\begin{array}{l}\text { Acima de } 150 \\
\text { empregados. }\end{array}$ & --- & $\begin{array}{c}\text { Superior a } R \$ \\
10.500 .000 \text { e inferior } \\
\text { ou igual a } R \$ 60 \\
\text { milhões. }\end{array}$ \\
\hline Grande empresa & ---- & --- & $\begin{array}{c}\text { Superior a } \mathrm{R} \$ 60 \\
\text { milhões. }\end{array}$ \\
\hline
\end{tabular}

Tabela 1: Comparativo de tamanho entre as empresas moveleiras 
Conforme pode ser observado na Tabela 1, uma empresa pode ser classificada como micro empresa de acordo com a primeira e ter uma outra classificação, segundo os parâmetros do BNDES (2004) e o SEBRAE (2003), o que pode resultar em conflitos e divergências com relação ao tamanho e ao faturamento. Nota-se também que o BNDES coloca a grande empresa em seus critérios de avaliação, o que não ocorre com a Abimóvel, que apenas tem classificação até a média empresa e o SEBRAE que tem parâmetro somente para as micro e pequenas empresas.

\subsection{A Indústria Moveleira no Rio de Janeiro}

A indústria moveleira do Estado do Rio de Janeiro possui as mesmas características das encontradas no restante do Brasil, conforme mencionado anteriormente e, ao que tudo indica, também sem a presença de tecnologia de ponta. Nota-se que o Estado do Rio de Janeiro não foi citado anteriormente como sendo um estado que se caracterize como um pólo moveleiro com certa expressividade dentro do país. Juntamente com o Espírito Santo, ele participa com apenas $5 \%$ da produção de móveis no Brasil. Na exportação, o Estado do Rio de Janeiro participa com $0,27 \%$ do total de móveis exportados pelo país (ABIMÓVEL, 2003). Assim sendo, em comparação com os outros pólos moveleiros e estados, a contribuição do Rio de Janeiro, como indústria moveleira, dentro do contexto nacional, ainda é bem pequena.

A realidade do setor, no Estado do Rio de Janeiro, é praticamente semelhante em todas as suas regiões e municípios. Segundo Cruz (2001), em seu estudo, no qual foi feita uma pesquisa com 50 empresas de diferentes cidades, escolhidas por grupos de empresários junto aos SENAI locais, o setor se caracteriza, principalmente, por: venda direta ao 
consumidor; produção por encomenda; métodos inadequados de desenvolvimento e produção dos produtos; baixa tecnologia; área de produção inadequada com relação ao layout; baixo preparo e pouca instrução e conhecimento por parte da mão-de-obra.

De acordo com o referido autor, estes fatores são os principais pontos das dificuldades internas apresentadas pelos empresários do setor no Estado. Outros fatores que contribuem para a sua baixa competitividade frente aos pólos moveleiros situados em outros estados são aqueles relacionados à ausência de produção local de: matérias-primas como, por exemplo, a madeira, laminados e chapas; acessórios e ferragens em geral e produtos de acabamento, tais como: tintas, vernizes e colas. Todos estes fatores acarretam um comprometimento dos custos industriais de cerca de $30 \%$.

No Estado do Rio de Janeiro não se encontram muitas empresas com plantas industriais automatizadas, sendo que a maior parte delas ainda utiliza métodos de produção e equipamentos desatualizados, destacando-se os problemas com: o layout e instalações inadequadas, a ausência de programação de controle e produção sistematizados, o desconhecimento de técnicas de gabaritos e dispositivos para beneficiamento e movimentação, estocagem inadequada de matérias-primas, desconhecimento de técnicas adequadas e modernas em acabamento de móveis e secagem da madeira, bem como de local e estrutura adequados para os mesmos, baixa qualificação profissional técnica e comportamental no setor de produção, desconhecimento do design de produto, ausência de ações de marketing comercial, desconhecimento de gestão de custos, dispersão empresarial física e institucional e a distância geográfica dos representantes comerciais de insumos.

Pode-se concluir que, no setor, dadas algumas exceções, predominam empresas com alto grau de deficiência técnica e estrutural. Para todas elas, é primordial uma estratégia que as leve a um patamar mais competitivo, tanto em relação às outras indústrias moveleiras brasileiras, quanto à busca de uma posição favorável em relação à exportação. Para que essas 
empresas possam se tornar mais competitivas, alguns pontos devem ser estudados e melhorados: 1) layout e instalações físicas (infra-estrutura); 2) métodos de produção - cursos e treinamento; 3) a capacitação dos recursos humanos; 4) melhoria do design, definição de estilo e desenvolvimento de novos produtos.

Estes pontos a serem melhorados pelas empresas, são os mesmos que podem ser aprimorados mediante o uso das estratégias da TBC para que uma empresa se torne baseada no tempo. Conforme exposto anteriormente, uma das estratégias da TBC é a adoção de uma manufatura ágil e flexível (WILLIS, 1998), com a simplificação e integração dos sistemas de produção, padronização e até mesmo automação dos processos (CARTER, MELNYK e HANDFIELD, 1995). Essa primeira abordagem levaria à reestruturação das instalações e facilidades das empresas, tornando-as flexíveis, com o layout e com infra-estrutura apropriados para uma resposta rápida às necessidades do mercado. Outro ponto a ser melhorado pelas empresas fluminenses são os métodos de produção, capacitação, treinamento e desenvolvimento do pessoal. Dumaine (1989) e Stalk e Hout (1990) argumentam que, para haver sucesso na implementação da TBC nas empresas, todos os níveis hierárquicos devem participar, envolver-se e comprometer-se com as mudanças. Inicialmente, o tempo e a velocidade devem ser considerados os parâmetros estratégicos das empresas pelas gerências, tornando parte não só da sua própria cultura quanto da dos funcionários. Conseqüentemente, o treinamento, o desenvolvimento e a qualificação do pessoal são de suma importância tanto para a melhoria dos processos pelas empresas quanto pelo sucesso da implementação da TBC. Outra estratégia abordada pela TBC é o desenvolvimento e introdução de novos produtos, sempre atendendo à necessidade dos clientes e do mercado consumidor. Aliás, o ponto forte da TBC é a pronta resposta ao cliente, não só na questão do tempo de entrega, mas principalmente, em relação aos produtos inovadores, com qualidade e design atraentes, correspondendo sempre às mudanças de mercado e às exigências dos clientes. Assim sendo, a 
TBC parece ser a estratégia competitiva de que o empresariado da indústria moveleira fluminense e mesmo de todo país necessita para chegar a um lugar de destaque e liderança no mercado. A TBC aparece como a grande estratégia para se alcançar esse objetivo.

\section{ESTUDO DE CASO}

Para melhor ilustrar a importância das estratégias da TBC para a alavancagem das empresas foi feito um estudo de caso com uma indústria moveleira situada na Região Serrana do Estado do Rio de Janeiro. O estudo foi baseado em entrevistas com a direção da empresa. Foram efetuadas visitas à empresa, onde foram coletados os dados para a pesquisa. A empresa, em questão, é de pequeno porte, tanto pelos parâmetros da Abimóvel (2003) quanto do BNDES (2004) e SEBRAE (2003), conforme a Tabela 1. Como a maioria das empresas moveleiras, esta também é de caráter familiar e está no mercado há 50 anos, produzindo móveis em geral, como também, móveis sob medida, de acordo com projetos estabelecidos pelos clientes, ou por arquitetos e possui três pontos de venda localizados no Estado do Rio de Janeiro.

Em vista de uma série de fatores, tanto econômicos quanto estruturais, a empresa está passando por uma fase de reestruturação. Para voltar a uma posição de destaque, que ocupava até o início da década de 90 dentro do Estado do Rio de Janeiro, a alta administração da empresa, após alguns estudos, resolveu adotar o tempo como gerenciador crítico e parâmetro estratégico e assim utilizar algumas estratégias propostas pela TBC. As medidas iniciais tomadas foram: reestruturação do layout de produção; melhoria dos processos produtivos, com formação de novas parcerias tanto na fabricação quanto fornecimento de novos produtos; melhoria do design e introdução de novos produtos (inovação); diminuição do tempo de entrega dos móveis, com a redução da burocracia interna e, melhoria da 
qualidade, com a introdução de novos produtos e participação do pessoal envolvido no processo produtivo.

Este trabalho foi iniciado em Setembro de 2003. Até então, a burocracia para a entrada de um pedido para a fabricação chegava a exigir até 07 dias, pois não havia um sistema integrado de informações entre os pontos de venda e a fábrica. As ordens de compra eram enviadas através de um "mensageiro" que as buscava nos pontos de venda duas vezes na semana. Com a informatização da entrada de dados e a conseqüente diminuição dos passos, leva-se apenas um dia para a entrada do pedido na produção, observando-se uma redução de $85 \%$.

O tempo para a fabricação de um móvel era de cerca de trinta dias. A empresa, em conjunto com seus funcionários, fez vários estudos para a redução do tempo de "set-up", tempo de movimentação de pessoal e material entre os setores de produção e para melhorar alguns aspectos relacionados ao layout e ao chão de fábrica. Portanto, o tempo de fabricação diminuiu para quinze dias e, no caso de alguns móveis, para dez dias, uma contração de 50\% e $65 \%$ respectivamente.

A distribuição dos móveis para os clientes sempre foi um serviço executado pela própria empresa, cujas entregas eram feitas mediante um roteiro programado pela expedição de acordo com a localização dos clientes. A expedição aguardava um número determinado de entregas dentro de uma localidade, para que estas fossem executadas, mesmo que os pedidos já estivessem prontos, gerando assim, uma série de atrasos para os clientes e insatisfação dos mesmos. Hoje, as entregas são feitas respeitando as datas e a programação estabelecida com os clientes.

Outra informação relevante é que a qualidade dos móveis melhorou sensivelmente: havia, em média uma reclamação com relação à qualidade dos mesmos a cada dez pedidos entregues, enquanto hoje, se tem cerca uma a cada trinta pedidos entregue, uma diminuição 
equivalente a 70\%. De acordo com a empresa, a meta é melhorar ainda mais. Com relação à introdução de novos produtos, não havia preocupação, por parte da alta administração, em renovar os produtos oferecidos aos clientes, existindo móveis com mais de 20 anos na linha de produção, com design obsoleto e material inadequado. Com a formação de parcerias para a introdução de componentes e materiais modernos e de qualidade superior aos utilizados pela empresa e a introdução gradativa de móveis mais modernos em conformidade com a necessidade dos consumidores, a empresa, aos poucos, está se reerguendo e retomando um lugar maior de destaque no mercado.

Observa-se que todo o processo de melhoria da empresa acima descrita está baseado em algumas das estratégias expostas pela TBC. A empresa conforme exposto por Stalk e Hout (1990), escolheu o tempo como parâmetro estratégico e, a partir deste ponto, envolveu todos os funcionários buscando formas para reduzir a burocracia interna (DUMAINE, 1989) e gerando uma diminuição no tempo da entrada do pedido na produção de 85\%, conforme demonstrado acima. A adoção de uma manufatura mais flexível e ágil (WILLIS, 1998) com um sistema mais integrado, simplificado e padronizado (CARTER, MELNYK e HANDFIELD, 1995) ocasionou uma queda de até $65 \%$ no tempo de fabricação dos pedidos, como já mencionado acima, diminuindo uma série de desperdícios tanto com relação ao tempo quanto ao que se refere ao estoque em processo, filas de espera e atrasos para os clientes com relação à entrega dos produtos. A introdução de novos produtos e materiais provenientes das parcerias com fornecedores e designers (STALK e HOUT, 1990), está contribuindo para o aumento das vendas e de "market-share".

Deve-se destacar que a empresa é conhecida pela alta qualidade de seus produtos e todos os seus fornecedores são escolhidos, principalmente, pelo critério de qualidade dos materiais fornecidos. O público alvo da empresa é, principalmente, composto pelas classes média-alta e alta, onde a qualidade, aliada à fidelidade dos seus consumidores, foi a máxima 
que manteve a empresa produzindo e funcionando até hoje. Em vista disso, as estratégias da TBC, quando ocorre o real comprometimento das pessoas envolvidas, podem, realmente levar uma empresa a uma posição de destaque sustentável, garantindo uma relação mais estreita com seus consumidores em relação às suas necessidades, gerando assim, uma fidelidade sólida dos mesmos, principalmente, em relação ao futuro. Isso ficou claro no estudo de caso, que lidou com uma pequena empresa moveleira situada no Rio de Janeiro, um estado que ao que tudo indica, não se destaca no setor de móveis no contexto brasileiro frente aos outros da nação.

\section{CONCLUSÃO}

A competição baseada no tempo como estratégia competitiva quando aplicada com o respaldo e engajamento de todos os envolvidos no processo, da alta administração ao mais baixo escalão hierárquico da organização, parece ser uma estratégia que realmente leva a empresa a uma posição de destaque e liderança, não só as de manufatura quanto às de serviço. A TBC pode ser aplicada a qualquer tipo de negócio, bastando que se tenha em foco o pronto atendimento às necessidades do cliente e do mercado consumidor, com qualidade e com o menor tempo possível para a execução das tarefas envolvidas no processo.

Como o enfoque é atender ao cliente com produtos inovadores, por intermédio de um atendimento especial, diferenciação e qualidade, as empresas baseadas no tempo são as que estabelecem os passos e o ritmo do mercado, estando na dianteira dos negócios e mantendo os seus concorrentes atrás. Portanto, são essas empresas que têm uma margem de lucro maior, melhor posição de mercado, maior "market-share", e conseqüentemente, uma liderança sustentável. 
O estudo de caso mostrou que a aplicação da TBC na empresa moveleira em questão e a consequiente redução do tempo, a partir da integração dos sistemas, da redução do tempo de "set-up", de movimentação de pessoal e material e melhoria do layout possibilitou reduções significativas do tempo de processamento de pedidos em $85 \%$ e da fabricação dos móveis de até $65 \%$, de acordo com os indicadores citados anteriormente. Em vista disso, muitos desperdícios foram eliminados, influenciando todo o processo de fabricação, diminuindo as filas, o estoque em processo e uma série de custos associados.

Os atrasos relacionados aos produtos afetavam as entregas e geravam grande insatisfação por parte dos clientes. A aplicação da TBC fez com que os atrasos fossem sanados, acarretando uma maior integração da empresa com os seus clientes e suas necessidades. A melhoria da qualidade foi outro fator relevante após a aplicação da referida estratégia. A inovação e a introdução de novos produtos de acordo com as necessidades dos clientes tornou a empresa mais conectada ao mercado e ao seu público-alvo, reconstruindo assim, uma fidelidade sólida e as bases para o futuro em relação ao eu crescimento e desenvolvimento, bem como a conquista de uma posição de destaque sustentável frente aos seus concorrentes.

\section{REFERÊNCIAS BIBLIOGRÁFICAS}

ASSOCIAÇÃO BRASILEIRA DAS INDÚSTRIAS DO IMOBILIÁRIO. Panorama do Setor Moveleiro do Brasil. São Paulo, Abimóvel dez. 2003, p.03.

BNDES. Porte da Empresa. Disponível em:

< http://www.bndes.gov.br/clientes/porte/porte.asp >. Acesso em: 11 mar 2004.

CARTER, Philip L.; MELNYK, Steven A.; HANDFIELD, Robert B. Identifying the Basic Strategies for Time-Based Competition. Production and Inventory Management Journal, First Quarter, Vol. 36, n. 1, pp. 65-70. 1995.

CRUZ, Demetrius Vasquez. O Setor Moveleiro no Estado do Rio de Janeiro. FIRJAN, Rio de Janeiro, Vol. 1, pp 1-22, abril. 2001. 
DE TONI, Alberto; MENEGHETTI, Antonella. Traditional and Innovative Paths towards Time-Based Competition. International Journal of Production Economics, 66, pp. 255268. 2000.

DUMAINE, Brian. How Managers Can Succeed Through Speed, Fortune, pp. 30-35. 13 February. 1989.

FORMÓBILE. Guia de Referência da Indústria Moveleira. Revista Móbile, Curitiba: Formóbile, 2004, p. 15.

GAITHER, Norman; FRAZIER, Greg. Administração da Produção e Operações. 8 ed. São Paulo: Pioneira Thomson Learning, 2001.

HUM, Sin-Hoon; SIM, Hoon-Hong. Time-Based Competition: Literature Review and Implications for Modeling. International Journal of Operations and Production Management, Vol. 16, No. 1, pp. 75-90. 1996.

SCHAENZER, Brian. The Crunch - Time-Based competition means moving beyond price and quality, Metal Technology Quarterly, 4A. 2000.

SERVIÇO BRASILEIRO DE APOIO ÀS MICRO E PEQUENAS EMPRESAS (Brasil). Guia Passo a Passo - Legalização de Empresas. Rio de Janeiro: Sebrae, 2003.

STALK, George JR. Time - The Next Source of Competitive Advantage. Harvard Business Review, pp. 41-51. July- August .1988.

STALK, George JR; HOUT, Thomas M. Competing Against Time: How Time-Based Competition is Reshaping Global Markets. 1st edition. New York: Free Press, 1990.

STALK, Ceorge JR; WEBBER, Alan M. Japan's Dark Side of Time. Harvard Business Review, pp. 93-102. July- August. 1993.

WILLIS, Hillman T. Operational Competitive Requirements for the Twenty-First Century. Industrial Management \& Data Systems, Vol. 2, pp. 83-86. 1998. 